\title{
Letter to Editor: An Effective Method for Allocating the Number of Training Sessions Required for Each of the Structures in the Theory-based Interventions of Health Education
}

\author{
Rahman Panahi $^{1^{*}}$ (D), Fereshteh Osmani² (iD \\ 1. Department of Health Education \& Promotion, School of Medical Sciences, Tarbiat Modares University, Tehran, Iran. \\ 2. Department of Infectious Disease Research Center, Birjand University of Medical Sciences, Birjand, Iran.
}

\begin{tabular}{l|l}
$\begin{array}{l}\text { Use vour device to san } \\
\text { and read the article online }\end{array}$ & $\begin{array}{l}\text { Citration Panahi R, Osmani F. An Effective Method for Allocating the Number of Training Sessions Required for Each of the } \\
\text { Structures in the Theory-based Interventions of Health Education. Journal of Research and Health. 2020; 10(6):349-350. http:// } \\
\text { dx.doi.org/10.32598/JRH.10.6.1395.19 }\end{array}$ \\
dol: : http://dx.doi.org/10.32598/JRH.10.6.1395.19
\end{tabular}

\section{Dear Editor}

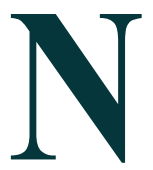

owadays, successful preventive education is carried out according to the well-known models resulted from the behavior change studies. Randomized controlled trials are the most accurate methods of studying health behaviors [1]. However, it is ambiguous how to allocate the number of required training sessions to each of the structures, in the theory-based interventions of health education. Most studies have emphasized on the information provided by the pretest and a review of previous studies to allocate the number of specific sessions for educational intervention [2, 3]. Moreover, some studies emphasized the results of a guideline study conducted before the intervention; the highest number of sessions have been allocated to the structures that had the greatest effect on behavior, in the guideline study [4]. However, there is no clear method to calculate the number of sessions required for each structure. Therefore, it is necessary to provide a simple and efficient method in this regard.

Researchers desire the following method to calculate the number of training sessions for each construct. Ini- tially, they conduct a guided study and assign a specific contribution to each construct, based on the results of the regression equation (regardless of direct or indirect effect). Next, the highest predictability value (regression coefficient) of each construct in the adoption of behavior is divided into total roles (total regression coefficients). Then, the resulting number is multiplied by the total number of training sessions. The content should be merged and trained together in one or more sessions, for structures that have less than one session. The following example helps to understand the proposed method.

Suppose you want to run a training program based on the health belief model constructs, in smoking prevention. Also, the results of the regression equation show that the largest share of educational interventions should be respectively allocated to the perceived susceptibility (with a predictability of 0.339 ), self-efficacy (with a predictability of 0.214 ), perceived benefits (with a predictability of 0.129 ), perceived barriers (with a predictability of 0.066 ), and perceived severity (with a predictability of 0.065 ) [5].

Assuming four sessions for the training intervention, the number of training sessions assigned to each construct is estimated as follows: perceived susceptibility (1.67 sessions), perceived self-efficacy (1.05 sessions),

\footnotetext{
* Corresponding Author:

Rahman Panahi, PhD.

Address: Department of Health Education \& Promotion, School of Medical Sciences, Tarbiat Modares University, Tehran, Iran.

Phone: +98 (912) 8630373

E-mail: peimanpamahi63@yahoo.com
} 
perceived benefits (0.62 sessions), perceived barriers (0.33 sessions), and perceived severity ( 0.33 sessions $)$. The two constructs of perceived barriers and perceived benefits (given that each of them contributes less than one session) should be merged and trained in one session. This integration should take place for the perceived severity construct, also, the training with the perceived susceptibility construct should be conducted in two sessions. The self-efficacy construct will also include one session out of the four training sessions.

According to the foregoing, the proposed method can be considered as a simple, efficient, and rational method for allocating the number of training sessions required for each construct in the theory-based interventions of health education.

\section{Ethical Considerations}

\section{Compliance with ethical guidelines}

There were no ethical considerations to be considered in this research.

Funding

This research did not receive any grant from funding agencies in the public, commercial, or non-profit sectors.

\section{Authors' contributions}

Both authors equally contributed to preparing this article.

\section{Conflict of interest}

The authors declared no conflict of interest.

\section{References}

[1] Glanz K, Rimer BK, Viswanath K, editors. Health behavior and health education: Theory, research, and practice. $4^{\text {th }}$ editor. San Francisco: Jossey-Bass; 2008. https://books.google. com/books?id=1xuGErZCfbsC\&dq

[2] Khalilipour Darestani M, Panahi R. [Effect of education on promoting preventive behaviors of premenstrual syndrome in female adolescents: Health belief model application (Persian)]. J Educ Community Health. 2017; 4(2):44-54 [DOI:10.21859/jech.4.2.44]

[3] Kazemi A, Ehsanpour S, Nekoei-Zahraei NS. A randomized trial to promote health belief and to reduce environmental tobacco smoke exposure in pregnant women. Health Educ Res. 2012; 27(1):151-9. [DOI:10.1093/her/cyr102] [PMID]
[4] Zare Mirakabad F, Dehghani Tafti AA, Rashidi Meybodi F Dehghani A, Rahaei Z. [Developing and evaluating a health belief model-based educational program on oral hygiene behaviors among child-wanting women in Mehriz, Yazd (Persian)]. Toloo-e-Behdasht. 2018; 17(3):52-63. https:/ / www.sid. ir/en/journal/ViewPaper.aspx?ID=710863

[5] Panahi R, Ramezankhani A, Tavousi M, Osmani F, Niknami Sh. [Predictors of adoption of smoking preventive behaviors among university students: Application of health belief model (Persian)]. J Educ Community Health. 2017; 4(1):35-42. [DOI:10.21859/jech.4.1.35] 